suggested the presence of a submarine volcano in eruption. The author of this article postulates a tectonic fracture stretching along an arc from the Ellersmere Land to the Tainyr peninsula. Along this line the following newly discovered features can be located: the problematic volcano, dredged volcanic glass and basaltic hornblende, the latter being also found in other localities of the Arctic Ocean.

\section{Seed Transmission of Plant Virus Diseases}

OF the considerable number of known plant virus diseases, only some furty-five are reported to be seedtransmitted, and of these only a few cases of actual embryo infection are known. N. C. Crowley, who has already demonstrated the presence of virus inhibitors in the seeds of several species, but not of virus inactivators, has now made further contributions on this topic (Austral. J. Biol. Sci., 10, 443 and 449; 1957). He has shown, by growing tomato embryos in media containing the virus, that there is no evidence for the presence of virus-inactivating substances in the embryos. Evidence is presented that whereas some of the highly infectious viruses commonly infect the seed testa, and even the endosperm, the developing embryo usually, and typically, remains uninfected. Since it has not been possible to obtain evidence of the presence of virus-inactivating agents in either the endosperm or the embryo, the favoured hypothesis to account for the rarity of seed-transmission is that the absence of plasmodesmatal connexions between the embryo and its tissue environment prevents its becoming infected. In a series of critical experiments, using well-known viruses and hosts, Crowley has shown to what extent the testa, the endosperm and the embryo may become infected in different cases. Again, all the evidence obtained indicates that the absence of seedtransmission of highly infectious viruses cannot be explained except in terms of the plasmodesmatal hypothesis. The alternative hypotheses (1) that the viruses induce sterility, (2) that the hosts contain inactivating substances, and (3) that developing embryos inactivate virus particles in the surrounding medium, are not validated by any evidence so far obtained. In the case of those virus diseases, for example, bean mosaic virus, that are seed-transmitted, this appears to depend on the ability of the virus to infect the microspores, macrospores or embryo sac before fertilization; but embryos themselves seem to be singularly free from infection. As the author points out, since natural selection would tend to eliminate any line of plants readily subject to the seed-transmission of a severe virus disease, the rarity of the latter phenomenon finds a simple and direct explanation.

\section{Medical Research Council Travelling Awards}

The Medical Research Council has made the fol lowing travelling awards for the academic year 1958-59. Rockefeller Travelling Fellowships in Medicine: Dr. G. Burnstock, Department of Pharmacology, Oxford; Mr. P. J. Holloway, Medical Research Council Laboratories, Hampstead; Mr. W. B. Jennett, lecturer in neurosurgery, University of Manchester; Dr. A. P. Mathias, lecturer in biochemistry, University College, London; Dr. R. P. Michael, Department of Experimental Neuroendocrinology, Institute of Psychiatry, Maudsley Hospital, London; Dr. P. H. A. Sneath, National Institute for Medical Research, Mill Hill. Lederle Travelling Fellowship in Medicine: Dr. R. J. Linden, lecturer in physiology, University of Leeds. Alexander Pigott Wernher Memorial Travelling Fellowship in Ophthalmology and Otology: Dr. G. B. Arden, Institute of Ophthalmology, London. French Exchange Scholarships in Medical Science: Miss J. E. Cremer, Medical Research Council Toxicology Research Unit, Carshalton, Surrey; Miss S. Reiman, Institute of Psychiatry, Maudsley Hospital, London.

Travelling Fellowships in Medicine have been awarded by the Eli Lilly Company of Indianapolis, after nomination by the Medical Research Council, to the following candidates : Mr. J. D. Griffiths, St. Bartholomew's Hospital, London; Dr. C. W. M. Wilson, lecturer in pharmacology and therapeutics, University of Liverpool. Travelling Fellowships in Medical Science have also been awarded by the United States Public Health Services, National Institutes of Health, Bethesda, Maryland, after nomination by the Medical Research Council, to the following candidates: Dr. B. S. Hartley, Department of Biochemistry, University of Cambridge; Dr. K. W. Cross, St. Mary's Hospital Medical School, London; Dr. A. Doig, Royal Infirmary, Edinburgh.

\section{Announcements}

THE Ministry of Supply announces that Dr. J. S. McPetrie has been appointed director-general of Electronics Research and Development in succession to Dr. D. H. Black.

A MeETing of the Photobiology Group on "Some Aspects of the Physiology of Vision" is to be held in the University Laboratory of Physiology, Oxford, during September 26-27. Registration forms and further details can be obtained from the chairman of the Photobiology Group, Dr. M. H. Pirenne, University Laboratory of Physiology, Oxford.

The Radio Frequency Spectroscopy Group (chairman, Prof. E. R. Andrew, Bangor) is to hold a conference on "Applications of Magnetic Resonance to Solid State Physics" at King's College, Newcastle upon Tyne (University of Durham), during September 22-23. The programme includes contributions on electron resonance of colour centres and iron group impurities in ionic crystals, nuclear resonance in ionic solids, electron spin, nuclear and cyclotron resonance in semi-conductors. Further particulars and application forms can be obtained from Dr. E. E. Schneider, King's College, Newcastle upon Tyne.

AN international conference on "Small Angle X-ray Scattering from Metals" will be held at Midwest Research Institute, Kansas City, Missouri, during September 23-25. The purpose of the meeting is to bring together active workers in the field to discuss the origin of the scattering as it relates to the crystal structure of metals. Arrangements for the conference have been made by the following committee: C. S. Barrett, Institute for Study of Metals, University of Chicago ; Paul A. Beck, University of Illinois ; W. W. Beeman, University of Wisconsin ; and J. C. Grosskreutz (chairman), Midwest Research Institute, Kansas City, Missouri, from whom further information can be obtained. Financial support is being provided by the National Science Foundation, the Office of Ordnance Research, the Office of Naval Research, the Wright Air Development Center, U.S. Air Force, and Midwest Research Institute. The proceedings will be published as a special section of the Journal of Applied Physics. 